\title{
Florian Wilk
}

Jesus und die Völker in der Sicht der Synoptiker 


\title{
Beihefte zur Zeitschrift für die neutestamentliche Wissenschaft \\ und die Kunde der älteren Kirche
}

\author{
In Verbindung mit \\ James D. G. Dunn - Richard B. Hays \\ Hermann Lichtenberger \\ herausgegeben von \\ Michael Wolter
}

Band 109

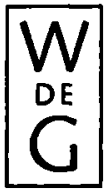

Walter de Gruyter - Berlin · New York

2002 
Florian Wilk

\section{Jesus und die Völker in der Sicht der Synoptiker}

Walter de Gruyter - Berlin - New York 2002 
Als Habilitationsschrift auf Empfehlung der Theologischen Fakultät der Universität Jena gedruckt mit Unterstützung der Deutschen Forschungsgemeinschaft.

Gedruckt auf säurefreiem Papier,

das die US-ANSI-Norm über Haltbarkeit erfüllt.

Die Deutsche Bibliothek - CIP-Einbeitsaufnabme

Wilk, Florian:

Jesus und die Völker in der Sicht der Synoptiker / Florian Wilk. Berlin ; New York : de Gruyter, 2001

(Beihefte zur Zeitschrift für die neutestamentliche Wissenschaft und die Kunde der älteren Kirche ; Bd. 109)

Zugl.: Jena, Univ., Habil.-Schr. 2000

ISBN 3-11-017179-1

(C) Copyright 2001 by Walter de Gruyter GmbH \& Co. KG, D-10785 Berlin

Dieses Werk einschließlich aller seiner Teile ist urheberrechtlich geschützt. Jede Verwertung außerhalb der engen Grenzen des Urheberrechtsgesetzes ist ohne Zustimmung des Verlages unzulässig und strafbar. Das gilt insbesondere für Vervielfältigungen, Übersetzungen, Mikroverfilmungen und die Einspeicherung und Vetarbeitung in elektronischen Systemen.

Printed in Germany

Umschlaggestaltung: Christopher Schneider, Berlin

Druck und buchbinderische Verarbeitung: Hubert \& Co., Göttingen 